\title{
On the profile of frequency dependent dielectric properties of $(\mathrm{Ni} / \mathrm{Au}) / \mathrm{GaN} / \mathrm{Al}_{0.3} \mathrm{Ga}_{0.7} \mathrm{~N}$ heterostructures
}

\author{
Z. Tekeli a , M. Gökçen ${ }^{\text {b,* }}$, Ş. Altındal a , S. Özçelik ${ }^{a}$, E. Özbay ${ }^{c, d}$ \\ ${ }^{a}$ Department of Physics, Faculty of Arts and Sciences, Gazi University, 06500 Ankara, Turkey \\ ${ }^{\mathrm{b}}$ Department of Physics, Faculty of Arts and Sciences, Duzce University, 81620 Duzce, Turkey \\ c Nanotechnology Research Center, Department of Physics, Bilkent University, Bilkent, 06800 Ankara, Turkey \\ ${ }^{\mathrm{d}}$ Nanotechnology Research Center, Department of Electrical and Electronics Engineering, Bilkent University, Bilkent, 06800 Ankara, Turkey
}

\section{A R T I C L E I N F O}

\section{Article history:}

Received 1 April 2010

Received in revised form 22 July 2010

Accepted 15 September 2010

Available online 12 October 2010

\begin{abstract}
A B S T R A C T
The voltage $(V)$ and frequency $(f)$ dependence of dielectric characteristics such as dielectric constant $\left(\varepsilon^{\prime}\right)$, dielectric loss $\left(\varepsilon^{\prime \prime}\right)$, dielectric loss tangent $(\tan \delta)$ and real and imaginary part of electrical modulus ( $\mathrm{M}^{\prime}$ and $M^{\prime \prime}$ ) of the $(\mathrm{Ni} / \mathrm{Au}) / \mathrm{GaN} / \mathrm{Al}_{0.3} \mathrm{Ga}_{0.7} \mathrm{~N}$ heterostructures have been investigated by using experimental admittance spectroscopy (capacitance-voltage $(C-V)$ and conductance-voltage $(G / w-V)$ ) measurements at room temperature. Experimental results show that the values of the $\varepsilon^{\prime}, \varepsilon^{\prime \prime}, \tan \delta$ and the real and imaginary parts of the electric modulus $\left(\mathrm{M}^{\prime}\right.$ and $\left.M^{\prime \prime}\right)$ obtained from the $C$ and $G / w$ measurements were found to be strong function of frequency and applied bias voltage especially in depletion region at low frequencies. These changes in dielectric parameters can be attributed to the interfacial GaN cap layer, interface polarization and a continuous density distribution of interface states and their relaxation time at metal/semiconductor interface. While the values of the $\varepsilon^{\prime}$ decrease with increasing frequencies, $\tan \delta, \mathrm{M}^{\prime}$ and $M^{\prime \prime}$ increase with the increasing frequency. Also, the dielectric loss $\left(\varepsilon^{\prime \prime}\right)$ have a local maximum at about frequency of $100 \mathrm{kHz}$. It can be concluded that the interface polarization can occur more easily at low frequencies with the number of interface states located at the metal/semiconductor interface.
\end{abstract}

(c) 2010 Elsevier Ltd. All rights reserved.

\section{Introduction}

The conduction mechanisms of gallium nitride (GaN) and its alloys are of great interest for use in electronic devices due to strong polarization effects and large energy band-gap. Therefore, GaN and some other compounds have been studied extensively for their applications in short wavelength optical and high-power/temperature devices, such as light emitting diodes (LEDs), laser diodes (LDs), metal-semiconductor (MS) Schottky barrier diodes (SBDs), metal-insulator-semiconductor high-electron-mobility transistors (MISHEMTs). GaN high-electron-mobility transistors (HEMTs) with Schottky/rectifier metal contact have demonstrated excellent highfrequency, high-power, high temperature and recently good microwave-noise characteristics [1-10]. The performance level of GaN/ AlGaN HEMT devices has increased rapidly over the last few years. Reliability, performance and life time combination of these devices are much higher than other devices. However, in order to improve the performance of these devices; the effects of surface passivation, dielectric layer $\left(\mathrm{Al}_{2} \mathrm{O}_{3}, \mathrm{Si}_{3} \mathrm{~N}_{4}\right)$ insertion, surface treatments with chemical or plasma have been investigated [11-19]. However, it still difficult to obtain a high quality GaN epilayer because of the

\footnotetext{
* Corresponding author.

E-mail address: muharremgokcen@duzce.edu.tr (M. Gökçen).
}

large lattice mismatch and large difference in the thermal expansion coefficients between the GaN film, sapphire, and SiC substrate. This fact causes threading dislocation density (DD) and interface states $\left(N_{s s}\right)$ generation, as grown by metal-organic chemical vapor deposition (MOCVD) in the GaN layer [13-19]. The reason for the existence of DD and $N_{s S}$ is the interruption of the periodic lattice structure at the surface, surface preparation, impurity concentration of semiconductor and the formation of barrier high at $\mathrm{M} / \mathrm{S}$ interface [20-22]. Since the surface capacitance $\left(C_{s s}\right)$ depends strongly on the frequency and applied bias voltage, both the capacitance-voltage $(C-V)$ and conductance-voltage $(G / w-V)$ characteristics are strongly affected [21-24]. Therefore, it is important to include the effect of frequency, applied bias voltage and interfacial insulator layer native or deposited in the investigation of electrical characteristics or dielectric properties.

In generally, GaN epitaxial layers are grown on sapphire $\left(\mathrm{Al}_{2} \mathrm{O}_{3}\right)$ or silicon carbide ( $\mathrm{SiC}$ ) substrate with lattice and thermal mismatch. Growth of GaN epitaxial layers on such substrates was done by using a low-temperature nucleation layer demonstrated a good crystal quality [25]. On the other hand, during a metal Schottky/ rectifier contact was performing on GaN high-electron-mobility transistors (HEMTs), commonly the GaN surface has been exposed to the air is contaminated with oxygen and carbon [26-28]. It is noteworthy that especially at low temperatures (LT) the GaN 
cap layer behaves like an insulator between the metals and semiconductor with extremely large sheet resistivity [29,30]. The purpose of the GaN cap layer is to prevent the reaction and inter-diffusion between the $(\mathrm{Ni} / \mathrm{Au})$ metals and semiconductor as well as to improve the respective retention properties [31]. Otherwise, this insulator layer between metal and semiconductor with GaN cap layer has several of the productive effect as passivate active dangling bonds at semiconductor surface and reduce the high gate-leakage current.

The aim of this study is to investigate the frequency and applied bias voltage dependence of the dielectric properties of the (Ni/Au)/ GaN/ $/ \mathrm{Al}_{0.3} \mathrm{Ga}_{0.7} \mathrm{~N}$ heterostructures using the admittance spectroscopy method $(C-V$ and $G / w-V)$ in the frequency range of $10 \mathrm{kHz}$ to $1 \mathrm{MHz}$ at room temperature. The dielectric parameters of these devices such as dielectric constant $\left(\varepsilon^{\prime}\right)$, dielectric loss $\left(\varepsilon^{\prime \prime}\right)$, loss tangent $(\tan \delta)$ and the real and imaginary part of $\left(M^{\prime}\right.$ and $\left.M^{\prime \prime}\right)$ electric modulus were obtained from the measured experimental capacitance $(C)$ and conductance $(G)$ values as function of frequency and applied bias voltage.

\section{Experimental procedures}

The $\mathrm{GaN} / \mathrm{Al}_{0.3} \mathrm{Ga}_{0.7} \mathrm{~N}$ heterostructures with a high-temperature (HT)-AlN buffer layer (BL), as was investigated in the present study, were grown on a c-face sapphire $\left(\mathrm{Al}_{2} \mathrm{O}_{3}\right)$ substrate by low-pressure metal organic chemical vapor deposition (MOCVD) method. Hydrogen was used as the carrier gas whereas trimethylgallium (TMGa), trimethylaluminum (TMAl), and ammonia $\left(\mathrm{NH}_{3}\right)$ were used as source compounds. Prior to the epitaxial growth, $\mathrm{Al}_{2} \mathrm{O}_{3}$ substrate was annealed at $1100{ }^{\circ} \mathrm{C}$ for $10 \mathrm{~min}$ to remove all surface contaminations. As shown in Fig. 1, a $15 \mathrm{~nm}$-thick AlN nucleation layer was deposited on an $\mathrm{Al}_{2} \mathrm{O}_{3}$ substrate at $840{ }^{\circ} \mathrm{C}$. Then, the reactor temperature was ramped to $1150{ }^{\circ} \mathrm{C}$ and an HT-AIN BL was grown, followed by a 2 min growth interruption in order to reach the growth conditions for GaN. GaN BL was grown at a reactor pressure of 200 mbar with growth temperature of $1070^{\circ} \mathrm{C}$ and growth rate of $2 \mu \mathrm{m} / \mathrm{h}$, approximately. Then, for a sample, a $2 \mathrm{~nm}$-thick HT-AlN inter layer was grown at a temperature of $1085{ }^{\circ} \mathrm{C}$ and a pressure of 50 mbar. Finally, a $25 \mathrm{~nm}$-thick AlGaN ternary layer and $2 \mathrm{~nm}$-thick GaN cap layer growth was carried out at a temperature of $1085^{\circ} \mathrm{C}$ and a pressure of $50 \mathrm{mbar}$, respectively.

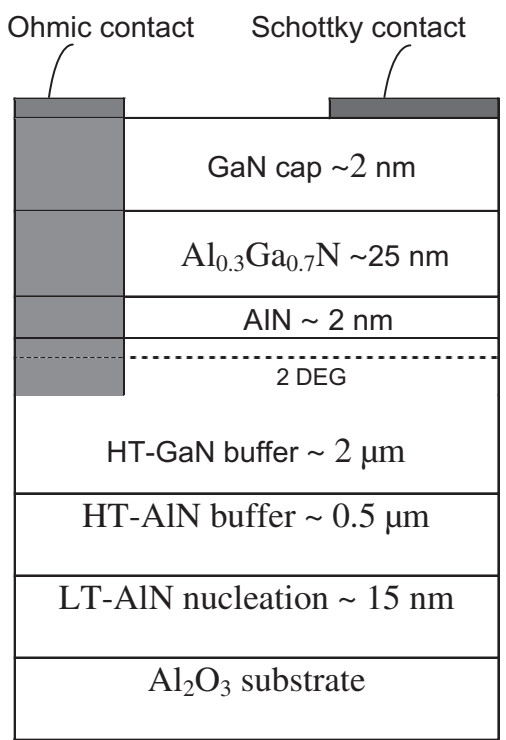

Fig. 1. Schematic diagram of the $(\mathrm{Ni} / \mathrm{Au}) / \mathrm{GaN} / \mathrm{Al}_{0.3} \mathrm{Ga}_{0.7} \mathrm{~N}$ heterostructures and $\mathrm{a}$ view of ohmic and Schottky contacts on the structures.
Prior to ohmic and rectifier contacts' formation, the samples were cleaned with acetone in an ultrasonic bath. Then, the sample was treated with boiling isopropyl alcohol for $5 \mathrm{~min}$ and rinsed in de-ionized (DI) water with resistivity of $18 \mathrm{M} \Omega \mathrm{cm}$. Immediately after the cleaning step, the samples were dipped in a solution of $\mathrm{HCl} / \mathrm{H}_{2} \mathrm{O}(1: 2)$ for $30 \mathrm{~s}$ in order to remove the surface oxides, and rinsed in DI water again for a prolonged time. The $\mathrm{Ti} / \mathrm{Al} / \mathrm{Ni} / \mathrm{Au}$ (200/2000/400/500 ̊) metals were thermally evaporated on the sample. After the metallization step, the contacts were annealed at $850{ }^{\circ} \mathrm{C}$ for $30 \mathrm{~s}$ in $\mathrm{N}_{2}$ ambient in order to form the ohmic contact. The same cleaning procedure used for ohmic contacts was again used prior to Schottky contact formation. The formation of the ohmic contact was followed by $\mathrm{Ni} / \mathrm{Au}(350 / 500 \AA)$ evaporation to form Schottky or rectifier contacts. Thus, the process of fabrication of $(\mathrm{Ni} / \mathrm{Au}) / \mathrm{GaN} / \mathrm{Al}_{0.3} \mathrm{Ga}_{0.7} \mathrm{~N}$ heterostructures was completed and its schematic diagram was given in Fig. 1 . The frequency dependence $C-V$ and $G / w-V$ measurements of these structures were performed at room temperature by using an HP 4192A LF impedance analyzer ( $5 \mathrm{~Hz}$ to $13 \mathrm{MHz}$ ) and test signal of $40 \mathrm{mV}_{\text {rms. }}$.

\section{Results and discussions}

In this study, the dielectric properties such as dielectric constant $\left(\varepsilon^{\prime}\right)$, dielectric loss $\left(\varepsilon^{\prime \prime}\right)$, dielectric loss tangent $(\tan \delta)$, real $\left(M^{\prime \prime}\right)$ and imaginary $\left(M^{\prime \prime}\right)$ parts of the electric modulus of $(\mathrm{Ni} / \mathrm{Au}) /$ $\mathrm{GaN} / \mathrm{Al}_{0.3} \mathrm{Ga}_{0.7} \mathrm{~N}$ heterostructures have been investigated over a wide frequency and voltage range from $10 \mathrm{kHz}$ to $1 \mathrm{MHz}$ and $-12 \mathrm{~V}$ to $12 \mathrm{~V}$, respectively, by using capacitance $(C)$ and conductance $(G / w)$ measurements at room temperature.

The frequency dependence of the $C-V$ and $G / w-V$ characteristics of the $(\mathrm{Ni} / \mathrm{Au}) / \mathrm{GaN} / \mathrm{Al}_{0.3} \mathrm{Ga}_{0.7} \mathrm{~N}$ heterostructures are given in Fig. 2a and b, respectively. It is clear that the $C-V$ and $G_{m} / w-V$ curves (Fig. 2) are quite sensitive to frequency. As can be seen from Fig. 2a, the measured capacitance is dependent on both the frequency and applied bias voltage. Especially in the depletion region, the values of $C$ increase with the decreasing frequency and shifts to reverse bias. Such behavior of $C$ shows that there are various kinds of interface states with different life times and they can follow ac signal especially at low and intermediate frequencies but cannot follow at high frequencies especially in the depletion region of structure. The capacitance of such an inhomogeneous layer at the semiconductor/insulator interface acts in a series with the insulator capacitance causing frequency dispersion $[9,20,21,23]$. Because at lower frequencies, the interface states can easily follow an ac signal and yield an excess capacitance $\left(C_{s s}\right)$ and conductance $\left(G_{s s}\right)$. This makes the contribution of interface state capacitance to the total capacitance negligibly small [21]. The increase in capacitance towards the low-frequency region may be also due to interfacial spacecharge formation, which would be effective at lower frequencies and hence the capacitance begins to decrease [21,32]. This situation has caused the split at $C-V$ and $G / w-V$ curves for each frequency and especially it is clear at $G / w-V$ curves that this split increases with the decreasing frequency.

The values of the $\varepsilon^{\prime}$ and $\varepsilon^{\prime \prime}, \tan \delta$ and electric modulus were evaluated from the data of $C$ and $G$ measurements for $(\mathrm{Ni} / \mathrm{Au}) / \mathrm{GaN} /$ $\mathrm{Al}_{0.3} \mathrm{Ga}_{0.7} \mathrm{~N}$ structures in frequency range of $10 \mathrm{kHz}$ to $1 \mathrm{MHz}$ at room temperature. The complex permittivity can be written $[22,23]$ as,

$\varepsilon^{*}=\varepsilon^{\prime}-j \varepsilon^{\prime \prime}$

where $\varepsilon^{\prime}$ and $\varepsilon^{\prime \prime}$ are the real and imaginary parts of complex permittivity of the dielectrics constants and $j$ is the imaginary root of $\sqrt{-1}$. The values of $\varepsilon^{\prime}$ and $\varepsilon^{\prime \prime}$, in the case of admittance measurements, can be expressed and follows: 

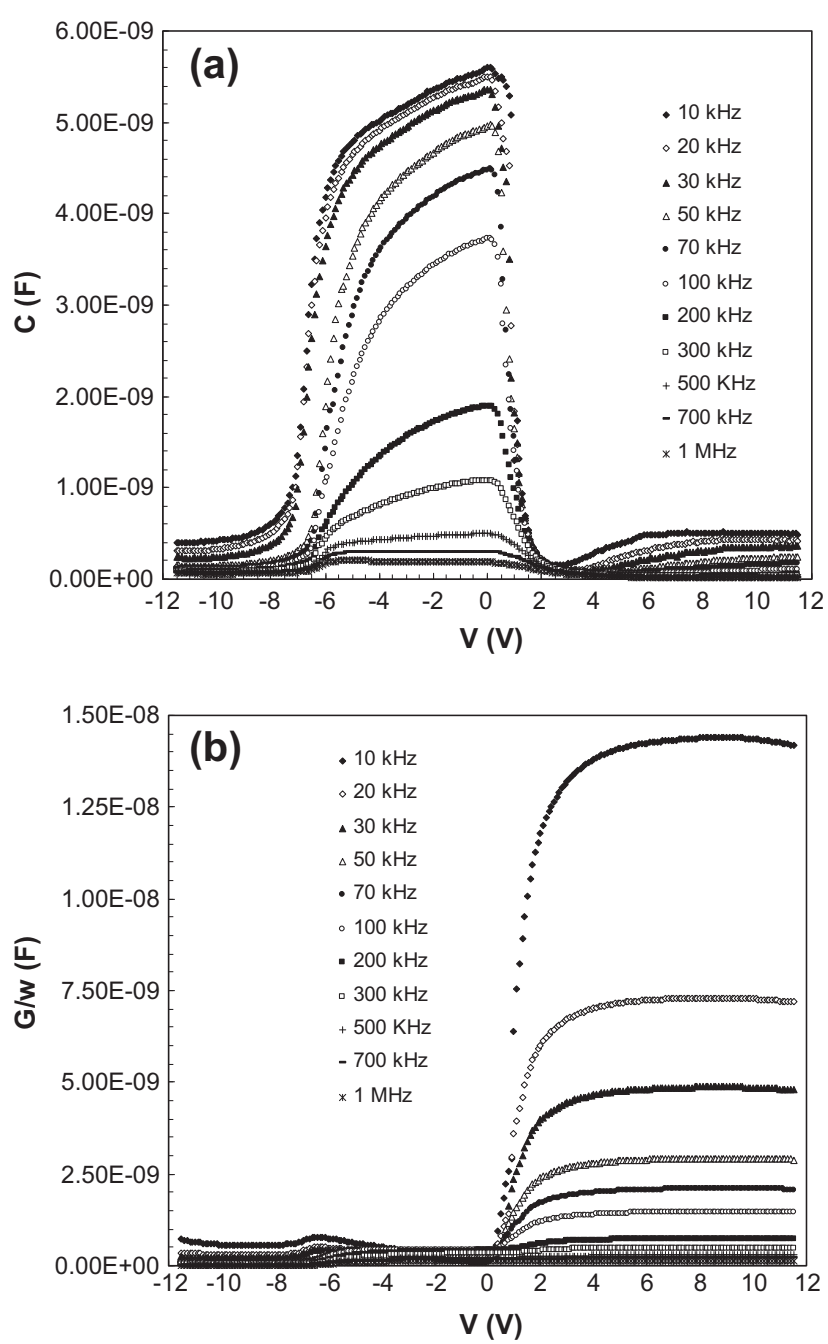

Fig. 2. Frequency dependence of the (a) $C-V$ (b) $G / w-V$ characteristics of (Ni/Au)/ $\mathrm{GaN} / \mathrm{Al}_{0.3} \mathrm{Ga}_{0.7} \mathrm{~N}$ heterostructure from $10 \mathrm{kHz}$ to $1 \mathrm{MHz}$ at room temperature.

$\varepsilon^{\prime}=\frac{C_{m} d_{o x}}{\varepsilon_{0} A}=\frac{C_{o x}}{C_{o}}$

$\varepsilon^{\prime \prime}=\frac{G_{m} d_{o x}}{\omega \varepsilon_{o} A}=\frac{G_{m}}{\omega C_{o}}$

The loss tangent $(\tan \delta)$ can be expired and follows [22,23]:

$\tan \delta=\frac{\varepsilon^{\prime \prime}}{\varepsilon^{\prime}}=\frac{G_{m}}{\omega C_{m}}$

where $C_{o}$ is the equivalent capacitance of the free space, $A$ is the area of the sample, $d_{o x}$ is the interfacial oxide layer thickness, $\varepsilon_{o}$ is the permittivity of free space-charge $\left(\varepsilon_{o}=8.85 \times 10^{-14} \mathrm{~F} / \mathrm{cm}\right)$ and $\omega(=2 \pi f)$ is the angular frequency.

Fig. 3a-c show the values of $\varepsilon^{\prime}, \varepsilon^{\prime \prime}$ and $\tan \delta$ of $(\mathrm{Ni} / \mathrm{Au}) / \mathrm{Al}_{0.3-}$ $\mathrm{Ga}_{0.7} \mathrm{~N} / \mathrm{AlN} / \mathrm{GaN}$ heterostructures as a function of voltage at various frequencies. Experimental results show that the values of $\varepsilon^{\prime}, \varepsilon^{\prime \prime}$ and $\tan \delta$ were found to be a strong function of voltage and the frequency especially at low frequencies. As can be seen from Fig. 3; the values of $\varepsilon^{\prime}, \varepsilon^{\prime \prime}$ and $\tan \delta$ of decrease as the frequency values are increased. The values of $\varepsilon^{\prime \prime}$ and $\tan \delta$ nearly remain constant in the inversion region while the $\varepsilon^{\prime}-V$ plot has a peak in this region. This increasing values of dielectric constant with the decreasing frequency could be attributed to the presence of a possible interface polarization mechanism since interface states can follow the
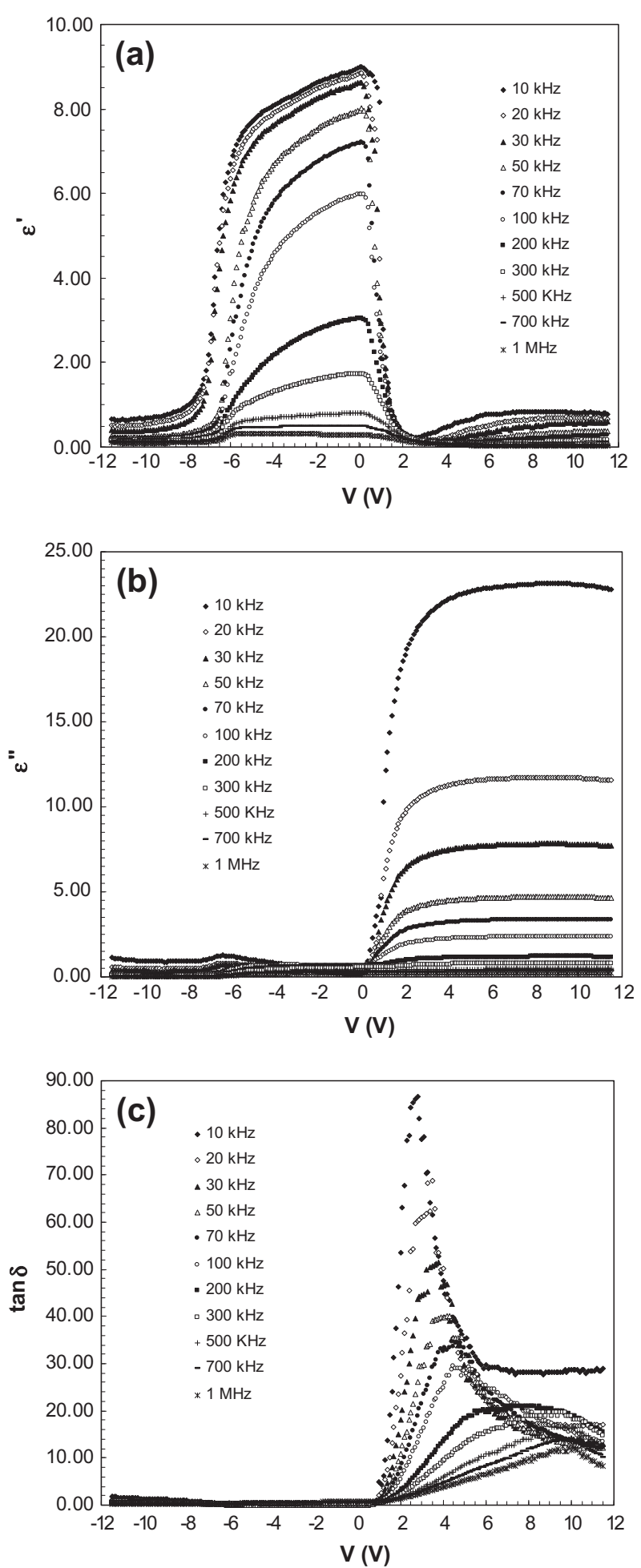

Fig. 3. The frequency dependence of the (a) $\varepsilon^{\prime}-V$, (b) $\varepsilon^{\prime \prime}-V$ and (c) $\tan \delta-V$ of $(\mathrm{Ni} / \mathrm{Au}) / \mathrm{GaN} / \mathrm{Al}_{0.3} \mathrm{Ga}_{0.7} \mathrm{~N}$ heterostructure measured at room temperature.

ac signal at low frequencies and contribute to both capacitance and the dielectric values. These dispersion in $\varepsilon^{\prime}$ and $\varepsilon^{\prime \prime}$ with frequency can be attributed to Maxwell-Wagner [33] and spacecharge polarization [34-38].

The decreases in frequency causes a loosening of the reliable results on dielectric properties by changing in dipole orientation and hence an increase in $\varepsilon^{\prime}, \varepsilon^{\prime \prime}$ and $\tan \delta$ frequency becomes apparent. Interface polarization reaches a constant value because of the fact 
that beyond a certain frequency of the external field, the electron hopping cannot follow the alternative field. These results show that the studied heterostructure device possess better dielectric properties for high frequency $(f>500 \mathrm{kHz})$.

Analysis of the complex permittivity $\left(\varepsilon^{*}\right)$ data within the $Z^{*}$ formalism $\left(Z^{*}=1 / Y^{*}=1 / j \omega C_{o} \varepsilon^{*}\right)$ is commonly used to separate the bulk and the surface phenomena and to determine the bulk dc conductivity of the material [23,39-42]. Generally, to extract as much information as possible, dielectric relaxation spectroscopy data are used in the electric modulus formalism [43]. Thus, the evaluation of the electric modulus as a function of frequency permits to detect the presence of relaxation processes in the studied materials [44]. In order to study dielectric dispersion in the $(\mathrm{Ni} / \mathrm{Au}) / \mathrm{Al}_{0.3} \mathrm{Ga}_{0.7} \mathrm{~N} /$ AlN/GaN heterostructures, we have used the complex electric modulus $\left(M^{*}\right)$ as defined by following relation [23,39-42] as,

$M^{*}=M^{\prime}+j M^{\prime \prime}=\frac{1}{\varepsilon^{*}}=\frac{\varepsilon^{\prime}}{\varepsilon^{\prime 2}+\varepsilon^{\prime 2}}+j \frac{\varepsilon^{\prime \prime}}{\varepsilon^{\prime 2}+\varepsilon^{\prime \prime 2}}$

where $j$ is equal to $(-1)^{1 / 2}$. The real $\left(M^{\prime}\right)$ and the imaginary $\left(M^{\prime \prime}\right)$ parts of complex electric modulus of $(\mathrm{Ni} / \mathrm{Au}) / \mathrm{GaN} / \mathrm{Al}_{0.3} \mathrm{Ga}_{0.7} \mathrm{~N}$ heterostructure were obtained from the values of $\varepsilon^{\prime}$ and $\varepsilon^{\prime \prime}$.

Fig. $4 \mathrm{a}$ and b show the real $\left(M^{\prime}\right)$ and the imaginary $\left(M^{\prime \prime}\right)$ parts of complex electric modulus $\left(M^{*}\right)$ versus voltage of this structure at
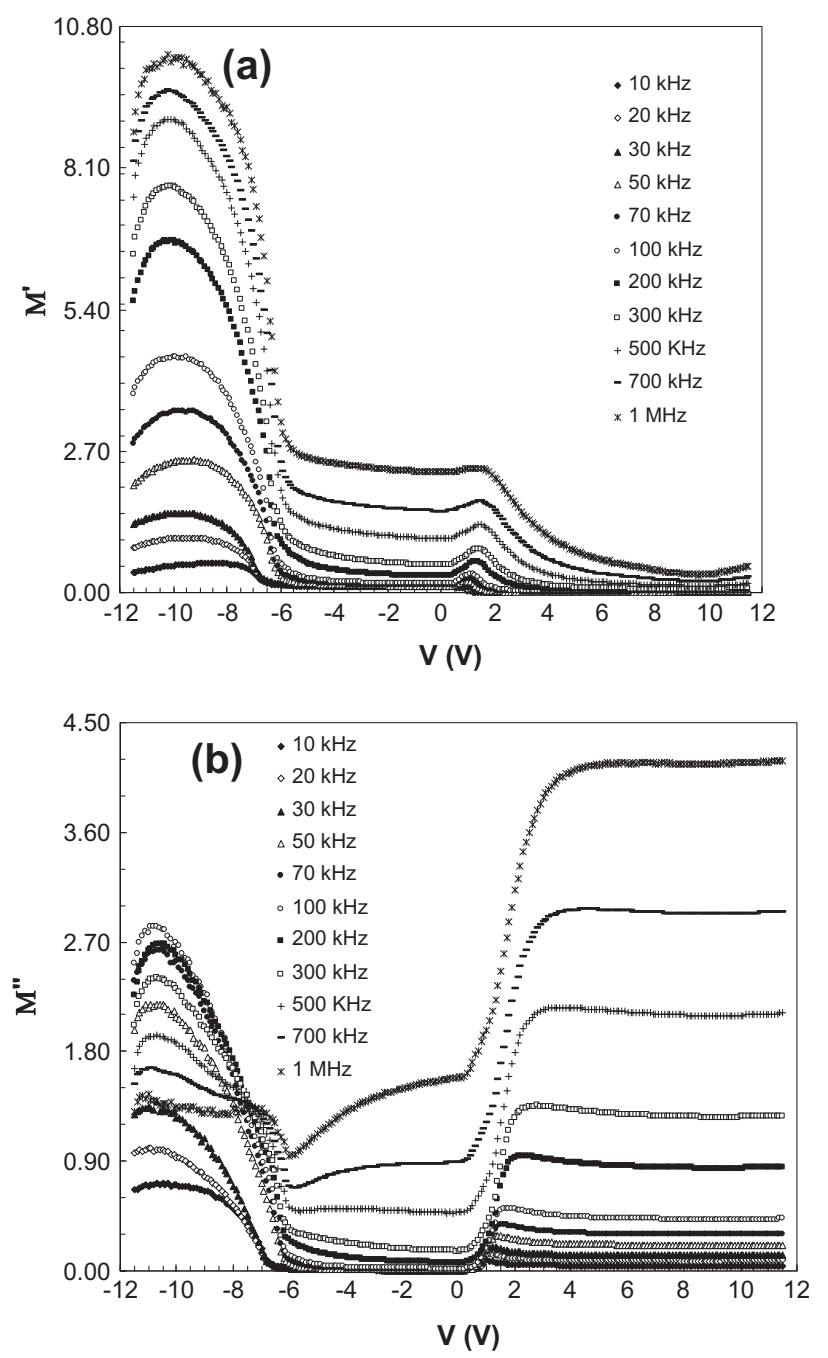

Fig. 4. The frequency dependence of the (a) the real $\left(M^{\prime}\right)$ and (b) imaginary parts $\left(M^{\prime \prime}\right)$ of complex electric modulus $\left(M^{*}\right)$ of $(\mathrm{Ni} / \mathrm{Au}) / \mathrm{GaN} / \mathrm{Al}_{0.3} \mathrm{Ga}_{0.7} \mathrm{~N}$ heterostructure measured at room temperature. various frequencies. Fig. 4 shows that, while the $M^{\prime}$ values have an evident frequency dispersion especially at negative voltage region, $M^{\prime \prime}$ values have it especially at positive voltage region. These values of $M^{\prime}$ and $M^{\prime \prime}$ increase with the increasing frequency. Similar studies have been reported in literature $[23,32,39]$. Especially in
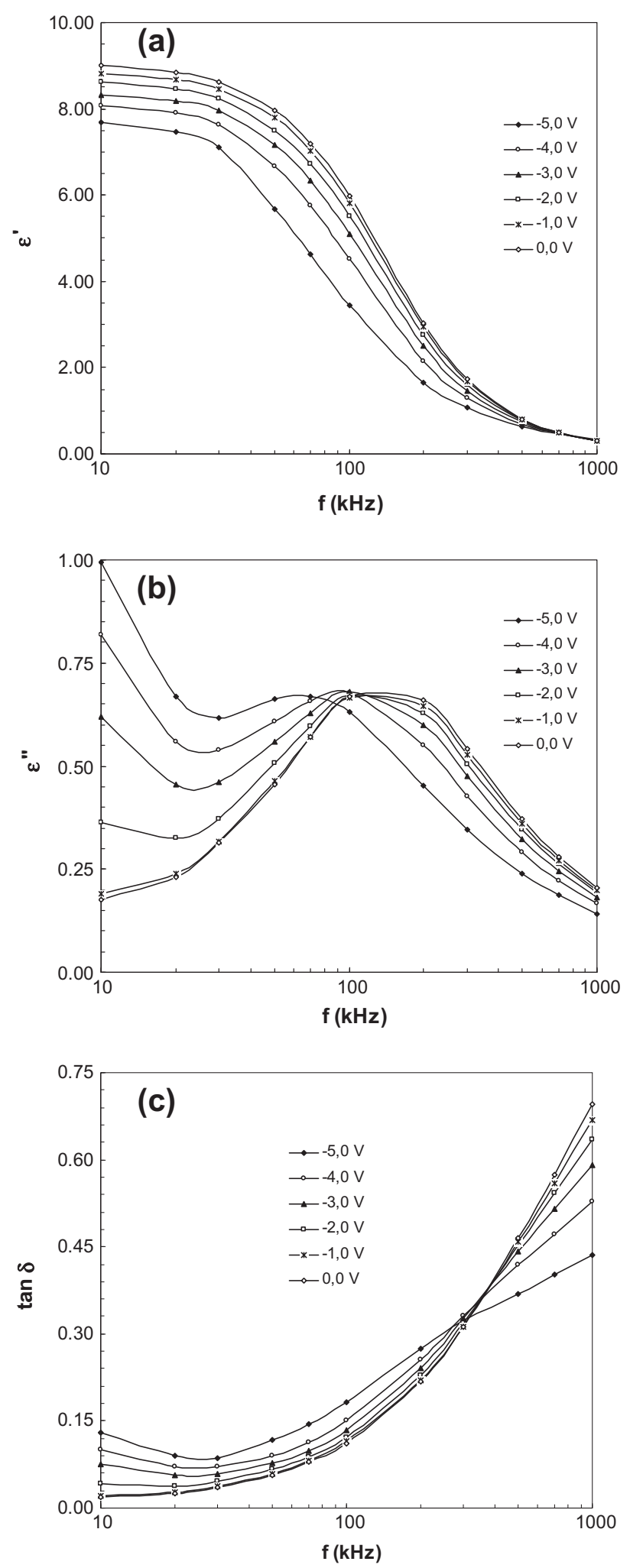

Fig. 5. The frequency dependence of (a) $\varepsilon^{\prime}$ (b) $\varepsilon^{\prime \prime}$ and (c) $\tan \delta$ of the (Ni/Au)/GaN/ $\mathrm{Al}_{0.3} \mathrm{Ga}_{0.7} \mathrm{~N}$ heterostructure at various applied bias voltages measured at room temperature. 
some regions, values of $M^{\prime}$ and $M^{\prime \prime}$ remain stable with the changing voltage. Such behavior of $M^{\prime}$ and $M^{\prime \prime}$ can be attributed to the fact that dielectric relaxation mechanisms of this structure were sensitive to frequency rather than applied voltage in these regions.

Fig. $5 \mathrm{a}-\mathrm{c}$ show the values of $\varepsilon^{\prime}, \varepsilon^{\prime \prime}$ and $\tan \delta$ of $(\mathrm{Ni} / \mathrm{Au}) / \mathrm{GaN} /$ $\mathrm{Al}_{0.3} \mathrm{Ga}_{0.7} \mathrm{~N}$ heterostructure as a function of frequency at various applied bias from $-5 \mathrm{~V}$ to $0 \mathrm{~V}$ with $1 \mathrm{~V}$ steps. As can be seen from Fig. 5; the value of $\varepsilon^{\prime}$ decreases with the increasing frequency while the value of $\tan \delta$ increases with the increasing frequency. Also the $\varepsilon^{\prime \prime}-f$ versus have a local maximum at $100 \mathrm{kHz}$ for each applied bias voltages. At above $100 \mathrm{kHz}$, the value of $\varepsilon^{\prime \prime}$ decreases with the increasing frequency. On the other hand, decreasing frequency causes voltage dispersion on the values of $\varepsilon^{\prime}, \varepsilon^{\prime \prime}$ and $\tan \delta-f$ curves. This dispersion is fairly clear in Fig. 5a. Increase in the values of $\varepsilon^{\prime}$ with the increasing applied bias voltage is evident especially at the low frequencies. The high values of $\varepsilon^{\prime}$ were observed at low frequencies and low negative bias voltage can be attributed to interfacial Maxwell-Wagner polarization [33] and space-charge polarization [45]. Both dispersion in $\varepsilon^{\prime}-f$ and $\varepsilon^{\prime \prime}-f$ curves are evident especially at low frequencies because of the reaction of interface traps and charge carriers in $(\mathrm{Ni} / \mathrm{Au}) / \mathrm{GaN} / \mathrm{Al}_{0.3} \mathrm{Ga}_{0.7} \mathrm{~N}$ heterostructure to frequency. At the high frequencies, dielectric polarization does not occur or it occurs weakly as seen from Fig. 5a.

Fig. 6a and b show the frequency dependence of real $\left(M^{\prime}\right)$ and imaginary $\left(M^{\prime \prime}\right)$ parts of the electric modulus of $(\mathrm{Ni} / \mathrm{Au}) / \mathrm{GaN} /$
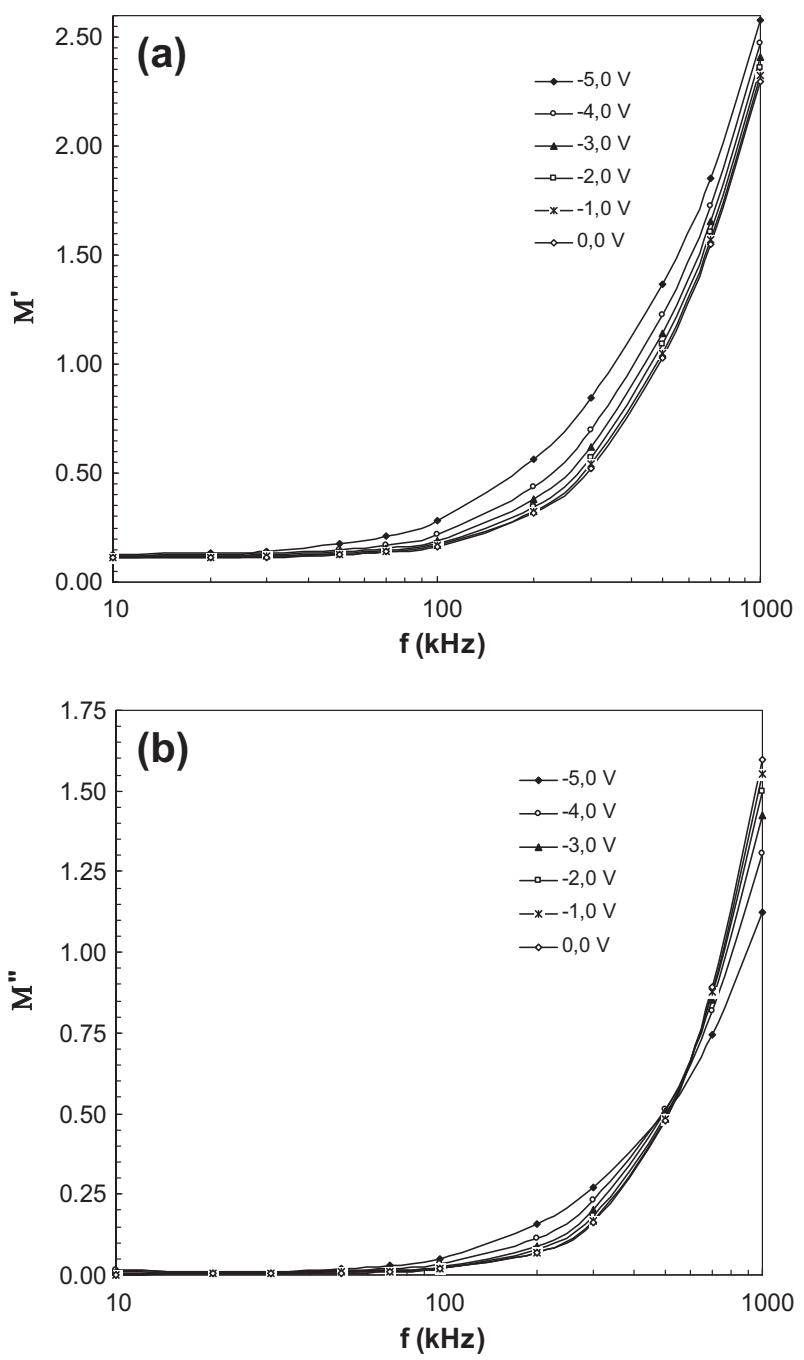

Fig. 6. The frequency dependence of (a) $M^{\prime}$ and (b) $M^{\prime \prime}$ of the (Ni/Au)/GaN/ $\mathrm{Al}_{0.3} \mathrm{Ga}_{0.7} \mathrm{~N}$ heterostructure at various voltages measured at room temperature.
$\mathrm{Al}_{0.3} \mathrm{Ga}_{0.7} \mathrm{~N}$ heterostructure at various applied bias voltages at room temperature. It is clear that the real and imaginary parts of the electric modulus increase with the increasing frequency. Increasing values of electric modulus with the increasing frequency was attributed to dielectric relaxation of polarizes electrons and dipoles in this structure. Voltage dispersion at $M^{\prime}-f$ and $M^{\prime \prime}-f$ curves is uncertain confront with $\varepsilon^{\prime}-f$ and $\varepsilon^{\prime \prime}-f$ versus. It shows that while both voltage and frequency are effective on dielectric polarization, frequency is more effective than voltage on dielectric relaxation.

\section{Conclusions}

In this study, dielectric properties of $(\mathrm{Ni} / \mathrm{Au}) / \mathrm{GaN} / \mathrm{Al}_{0.3} \mathrm{Ga}_{0.7} \mathrm{~N}$ heterostructures have been investigated in the frequency range of $10 \mathrm{kHz}$ to $1 \mathrm{MHz}$ in order to have a good interpretation of some main structure parameters such as the $\varepsilon^{\prime}, \varepsilon^{\prime \prime}, \tan \delta, \mathrm{M}^{\prime}$ and $M^{\prime \prime}$. These main parameters were evaluated from admittance spectroscopy $(C-V$ and $G / w-V)$ measurements at room temperature. Experimental results show that both $C$ and $G / w$ were quite sensitive to applied voltage and frequency especially at low frequencies. The high values of $C$ at low frequencies were attributed to the excess capacitance resulting from the interface states, which are in equilibrium with semiconductor that follows an ac signal. Therefore, the dielectric constant $\left(\varepsilon^{\prime}\right)$, dielectric loss $\left(\varepsilon^{\prime \prime}\right)$, loss tangent $(\tan \delta)$ and the electric modulus were also found a strong function of bias voltage and frequency. While the values of the $\varepsilon^{\prime}$ decrease with increasing frequencies, $\tan \delta$ and the electric modulus (real and imaginary parts) increase with the increasing frequency. Also, the dielectric loss $\left(\varepsilon^{\prime \prime}\right)$ have a local maximum at about frequency of $100 \mathrm{kHz}$. As a result GaN cap layer at $M / S$ interface behave like an insulator and it leads to a change in both electrical and dielectric properties especially at low frequencies.

\section{References}

[1] Kumar V, Lu W, Schwindt R, Kuliev A, Simin G, Yang J, et al. IEEE Electron Dev Lett 2002;23(8):455.

[2] Liu ZH, Arulkumaran S, Maung YKT, Teo KL, Foo SC, Sahmuganathan V, et al. IEEE Electron Dev Lett 2002;31(2):455.

[3] Tekeli Z, Altındal Ş, Çakmak M, Özçelik S, Çalışkan D, Özbay E. J Appl Phys 2007:102:054510.

[4] Çörekçi S, Öztürk MK, Akaoğlu B, Çakmak M, Özçelik S, Özbay E. J Appl Phys 2007;101:123502.

[5] Tut T, Biyikli N, Kimukin I, Kartaloğlu T, Aytur O, Unlu MS, et al. Solid-State Electron 2005;49:117.

[6] As DJ, Potthast S, Fernandez J, Lischka K, Nagasawa H, Abe M. Microelectron Eng 2006;83:34.

[7] Karataş S, Türüt A. Microelectron Reliab 2010;50:351.

[8] Farrell RA, Cherkaoui K, Petkov N, Amenitsch H, Holmes JD, Hurley PK, et al. Microelectron Reliab 2007;47:759.

[9] Dökme İ, Altındal Ş, Tunç T, Uslu İ. Microelectron Reliab 2010;50:39.

[10] Delmonte N, Watts BE, Chiorboli G, Cova P, Menozzi R. Microelectron Reliab 2007;47:682.

[11] Kim H, Schuette M, Jung H, Song J, Lee J, Lu W, et al. Appl Phys Lett 2006;89:053516.

[12] Kim H, Thompson RM, Tilak V, Prunty TR, Shealy JR, Eastman LF. IEEE Electron Dev Lett 2003;24:421.

[13] Yu H, Çalışkan D, Özbay E. J Appl Phys 2006;100:033501.

[14] Gaska R, Yang JW, Osinsky A, Chen Q, Asif Khan M, Orlov AO, et al. Appl Phys Lett 1998;72:707.

[15] Dadgar A, Hums C, Diez A, Bläsing J, Krost A. J Cryst Growth 2006;297:279.

[16] Demirezen S, Altındal Ş. Physica B 2010;405:1130.

[17] Arslan E, Şafak Y, Taşçıoglu I, Uslu H, Özbay E. Microelectron Eng 2010;87:1997.

[18] Çörekçi S, Usanmaz D, Tekeli Z, Çakmak M, Özçelik S, Özbay E. J Nanosci Nanotechnol 2008;8:640.

[19] Çörekçi S, Tekeli Z, Çakmak M, Özçelik S, Dinç Y, Zeybek O, et al. Mater Sci Semicond Process 2009;12:238.

[20] Sze SM. Physics of semiconductor devices. 2nd ed. New York: Wiley; 1981.

[21] Nicollian EH, Goetzberger A. Appl Phys Let 1965;7:216.

[22] Kar S, Narasimhan RL. J Appl Phys 1987;61(12):5353.

[23] Dökme İ, Altındal Ş, Gökçen M. Microelectron Eng 2008;85:1910.

[24] Mohammad SN, Salvador A, Morkoç H. Proc IEEE 1996;83:1420.

[25] Joshi BC, Mathew M, Joshi BC, Kumar D, Dhanavantri C. Pramana-J Phys 2010;74(1):135. 
[26] Bermudez VM, Koleske DD, Wickenden AE. Appl Surf Sci 1998;126:69.

[27] King SW, Barnak JR, Bremser MD, Tracy KM, Ronning C, Davis RF, et al. J Appl Phys 1998;84:5248.

[28] Shalish I, Shapira Y, Burnstein L, Salzman J. J Appl Phys 2001;89:390.

[29] Lee ML, Sheu JK, Su YK, Chang SJ, Lai WC, Chi GC. IEEE Electron Dev Lett 2004;25:593.

[30] Miller EJ, Dang XZ, Wieder HH, Asbeck PM, Yu ET, Sullivan GJ, et al. J Appl Phys 2000;87:8070

[31] Tekeli Z, Altındal Ş, Çakmak M, Özçelik S, Özbay E. Microelectron Eng 2008;85:2316.

[32] Prabakar K, Narayandass SK, Mangalaraj D. Phys Stat Sol (a) 2003;199(3):507.

[33] Bidault O, Goux P, Kchikech M, Belkaoumi M, Maglione M. Phys Rev B 1994;49:7868.
34] Symth CP. Dielectric behavior and structure. New York: McGraw-Hill; 1955.

35] Ranga Raju MR, Choudhary RNP, Ram S. Phys Stat Sol (b) 2003;239(2):480.

[36] Singh V, Kulkarni AR, Rama Mohan TR. J Appl Polym Sci 2003;90:3602.

[37] Mazen SA, Zaki HM. Phys Stat Sol (a) 2003;199(2):305.

[38] Maurya D, Kumar J, Shripal. J Phys Chem Solids 2005;66:1614.

[39] Gökçen M, Altuntaş H. Physica B 2009;404(21):4221.

[40] Gökçen M, Altuntaş H, Altındal Ş. Optoelectron Adv M 2008;2(12):833.

[41] Gökçen M, Altuntas H, Altındal S. Optoelectron Adv M 2008;2(12):838

[42] Mattsson MS, Niklasson GA, Forsgren K, Harsta A. J Appl Phys 1999;85(4):2185.

[43] Macedo PB, Moyniham CT, Bose R. Phys Chem Glass 1972;13:171.

[44] Pakma O, Serin N, Serin T, Altındal S. J Phys D Appl Phys 2008;41:215103.

[45] Kyristsis A, Pissis P, Grammatikakis J. J Polym Sci Polym Phys 1995;33:1737. 